\title{
Optimal Fiscal Policy When Migration is Feasible
}

\author{
Filippo Occhino*
}

August 2005

\begin{abstract}
This paper investigates how the feasibility of migration affects governments' optimal fiscal policies. We assume that households migrate towards economies where their welfare is higher, governments choose taxes and public expenditures to maximize a weighted sum of the households' welfare, welfare is increasing in public expenditures, and only distortionary labor income taxes are available. In isolated economies, the optimal fiscal policy implies that some households are net fiscal contributors, while other households are net fiscal beneficiaries. When households can migrate, however, governments compete for the households which are net fiscal contributors, and modify the fiscal policy in their favor, lowering their taxes and net fiscal contribution, and increasing their welfare. The magnitude of the effect increases with the sensitivity of migration to welfare. In the limiting case of free mobility, all households are zero net fiscal contributors.

Keywords: Optimal fiscal policy, Ramsey equilibrium, Migration, Fiscal competition, Mobility, Fiscal burden.

JEL Classification Number: E62
\end{abstract}

*Address: Department of Economics, Rutgers University, 75 Hamilton Street, New Brunswick NJ 08901. E-mail: occhino@rutgers.edu. Web: http://econweb.rutgers.edu/occhino/. 


\section{Introduction}

Migration and fiscal policy interact along several important dimensions. An extended literature, both theoretical and empirical, documents the response of migration and mobile factors to fiscal policy. Most relevantly for this paper, Razin and Sadka (2001, Part II) argue that the welfare state drives in low-skill migration and drives out high-skill migration. Several papers, like Storesletten (2000), focus on how migration affects fiscal variables, debt in particular, for given fiscal policies. Others, like Razin, Sadka and Swagel (2002), study how migration affects fiscal policy from a political economy perspective. This paper investigates theoretically how the feasibility of migration affects the fiscal policies optimally set by governments, abstracting from political economy arguments. It directly contributes to the literature on optimal policy with commitment, which stems from Lucas and Stokey (1983), extending its normative analysis to allow for migration. It is more generally related to the literature on fiscal competition surveyed by Wilson (1999), of which Honkapohja and Turunen-Red (2004) is a most recent example.

In this paper, we emphasize an effect leading to a symmetric general change of fiscal policies across all countries in response to migration feasibility. We assume that households migrate towards economies where their welfare is higher, governments choose taxes and public expenditures to maximize a weighted sum of the households' welfare, welfare is increasing in public expenditures, and only distortionary labor income taxes are available. The main result follows from the concept of a household's net fiscal contribution (or net fiscal burden), the difference between the taxes that the household pays to the government and the expenditures sustained by the government for that specific household. The addition of a positive net fiscal contributor to an economy benefits all other households in the economy, since it allows the government to decrease taxes or to increase public expenditures for all other households, while the addition of a net fiscal beneficiary hurts all other households. Hence, in their aim of maximizing a weighted sum of the households' welfare, governments have an incentive to attract net fiscal contributors and to discourage net fiscal beneficiaries. They do so by modifying the fiscal policy in favor of net fiscal contributors, lowering their taxes and net fiscal contribution, and increasing their welfare. In a general equilibrium where all economies 
are identical and all governments compete for net fiscal contributors, there are no migration flows, and the only effect is a general change of fiscal policies in favor of net fiscal contributors and at the expenses of net fiscal beneficiaries.

The magnitude of the effect depends on how feasible is migration. The more households are able and willing to migrate towards economies where their welfare is higher, the stronger is the effect. We model as exogenous the sensitivity of migration to welfare, which measures the magnitude of migration flows in response to welfare differences across economies. If households cannot migrate, the effect does not occur. As the sensitivity of migration to welfare increases, the magnitude of the effect increases, the equilibrium fiscal contribution of positive net fiscal contributors decreases, while the equilibrium fiscal contribution of fiscal beneficiaries increases. In the limiting case of free mobility, all households are zero net fiscal contributors.

The model predicts that, the more households are able and willing to migrate into and out of an economy, the smaller should be the observed differences across households' net fiscal contributions. Hence, differences across households' net fiscal contributions should be much smaller for economies like states and provinces, where households are more able and willing to migrate, than for economies like countries where the sensitivity of migration to welfare differences is much smaller. Also, differences across households' net fiscal contributions should decrease over time if the ability and willingness of households to migrate in response to welfare differences across countries increases.

In what follows, Section 2 describes the model, Section 3 defines the competitive equilibrium, Section 4 characterizes the optimal competitive equilibrium or Ramsey equilibrium, Section 5 determines the effect of migration feasibility on optimal fiscal policy and derives the results, and Section 6 concludes.

\section{Model}

The model is a one-period economy with several identical countries. In each country, there is a government, and $I$ different types of households. Households of the same type are identical, while households of different types differ only as to their labor productivity. Let $w_{i}>0$ be 
the number of type $i$ households, where $\sum_{i \in I} w_{i}=1$.

Each type $i$ household is endowed with $\bar{n}>0$ hours, and choose to work $n_{i} \in[0, \bar{n}]$ hours. Each hour of work produces $x_{i}>0$ units of a non-storable consumption good. Its private consumption is $c_{i} \geq 0$, while its per-capita public consumption is $g \geq 0$, independently of its type. The feasibility constraint is then

$$
\sum_{i \in I} w_{i} c_{i}+\sum_{i \in I} w_{i} g=\sum_{i \in I} w_{i} c_{i}+g \leq \sum_{i \in I} w_{i} x_{i} n_{i}
$$

Public consumption must be financed through distortionary labor income taxes. Let $\tau_{i}<1$ be the tax rate on labor income of type $i$ households.

Households' preferences are described by the utility function $u(c, n, g)$, which is twice continuously differentiable, strictly increasing in its first and third arguments $c$ and $g$, strictly decreasing in its second argument $n$, and strictly concave, and satisfies the Inada conditions $\lim _{c \rightarrow 0} u_{c}(c, n, g)=\infty$ for all $n, g, \lim _{n \rightarrow \bar{n}} u_{n}(c, n, g)=-\infty$ for all $c, g$, and $\lim _{g \rightarrow 0} u_{g}(c, n, g)=\infty$ for all $c, n$. Alternatively, in place of the second condition, one could assume that $\lim _{n \rightarrow+\infty} u_{n}(c, n, g)=-\infty$ for all $c, g$, and that $\bar{n}$ is large enough so that $n<\bar{n}$ is optimal in all the following optimization problems. The government's objective function is a weighted average of the households' utility functions. Let $\pi_{i}>0$ be the weight of type $i$ households in the government's utility function, where $\sum_{i \in I} \pi_{i}=1$.

The timing of the events is as follows. First, governments commit to a fiscal policy $\left\{g, \tau_{i}\right\}_{i \in I}$, then households choose whether to migrate or remain in their own country, and finally households choose the private allocation $\left\{c_{i}, n_{i}\right\}_{i \in I}$.

Proceeding backward, in the third stage, households solve a simple optimization problem, and choose their equilibrium allocation and utility.

In the second stage, given their optimal strategy in the third stage, households choose whether to migrate based on a comparison between their equilibrium utility in their own country and in other countries, taking into account all barriers and costs of migration. We model this decision assuming that the number of type $i$ households in each country is a continuously differentiable, strictly increasing function $w_{i}\left(u\left(c_{i}, n_{i}, g\right)\right)$ of their equilibrium utility in that country, for given equilibrium utility in other countries. We refer to the derivatives $w_{i}^{\prime}\left(u\left(c_{i}, n_{i}, g\right)\right)$ as the sensitivities of migration to welfare. When $w_{i}^{\prime}=0$, there is 
no migration. The larger the sensitivities $w_{i}^{\prime}$, the larger the response of the number of type $i$ households to changes in their equilibrium utility. In a more explicit model, the function $w_{i}\left(u\left(c_{i}, n_{i}, g\right)\right)$ would depend on the barriers and costs of migration as well as the number of countries. The larger the number of countries and the smaller the costs of migration, the larger the sensitivities $w_{i}^{\prime}$.

In the first stage, given the households' optimal strategies in the second and third stage, and given the fiscal policy of other governments, the government of each country chooses its fiscal policy to maximize its objective function. The government is constrained to choose among the set of fiscal policies which lead to a competitive equilibrium. Equivalently, the government chooses the Ramsey equilibrium, the competitive equilibrium where its utility is highest. We define it Ramsey equilibrium because the government's utility function only depends on the households' utility functions.

So far, we have described a model with one country, where all the interaction with other countries is summarized by the functions $w_{i}\left(u\left(c_{i}, n_{i}, g\right)\right)$. We now make use of the assumption that all countries are identical. We focus on a symmetrical equilibrium where all governments choose the same fiscal policy and the same Ramsey equilibrium. In this case, each household receives the same utility in all countries, no household migrates in equilibrium, and the number of type $i$ households $w_{i}$ in each country is constant and equal to an exogenous value $\bar{w}_{i}>0$. Hence, the effect of a general decrease in the costs of migration across all countries is to increase the sensitivities $w_{i}^{\prime}$ of migration to welfare without affecting the number of type $i$ households $w_{i}$.

\section{Competitive equilibria}

To study the optimization problem faced by the government in the first stage, we first introduce competitive equilibria. A competitive equilibrium is an allocation $\left\{c_{i} \geq 0, n_{i} \in\right.$ $[0, \bar{n}], g \geq 0\}_{i \in I}$, together with tax rates $\left\{\tau_{i}<1\right\}_{i \in I}$ such that:

- Given $\left\{g, \tau_{i}\right\}_{i \in I},\left\{c_{i}, n_{i}\right\}_{i \in I}$ solve the following households' problems:

For $i \in I: \max _{\left\{c_{i} \geq 0, n_{i} \in[0, \bar{n}]\right\}} u\left(c_{i}, n_{i}, g\right)$ subject to $c_{i}=\left(1-\tau_{i}\right) x_{i} n_{i}$ 
- The government budget constraint is satisfied

$$
\sum_{i \in I} w_{i} \tau_{i} x_{i} n_{i}=\sum_{i \in I} w_{i} g
$$

- The market for consumption goods is in equilibrium:

$$
\sum_{i \in I} w_{i}\left(c_{i}+g\right)=\sum_{i \in I} w_{i} x_{i} n_{i}
$$

By Walras' Law, the households' budget constraints and the consumption goods market equilibrium condition imply that the government budget constraint is satisfied.

From the necessary conditions of the household's problem,

$$
\text { For } i \in I:\left(1-\tau_{i}\right) x_{i}=\frac{-u_{n}\left(c_{i}, n_{i}, g\right)}{u_{c}\left(c_{i}, n_{i}, g\right)}
$$

These conditions, evaluated in equilibrium, express the tax rates as functions of the allocation.

Substituting the previous expressions for the tax rates into the households' budget constraints, we obtain the implementability constraints

$$
\text { For } i \in I: u_{c}\left(c_{i}, n_{i}, g\right) c_{i}+u_{n}\left(c_{i}, n_{i}, g\right) n_{i}=0
$$

An allocation $\left\{c_{i} \geq 0, n_{i} \in[0, \bar{n}], g \geq 0\right\}_{i \in I}$ is implementable if it satisfies the feasibility constraint (1) with equality and the implementability constraints (2). As in Lucas and Stokey (1983), competitive equilibria are implementable allocations together with their associated tax rates.

\section{Ramsey equilibrium}

In the first stage, the government chooses the Ramsey equilibrium, the competitive equilibrium where its utility is highest. The government takes into account the households' responses in the second and third stage to its choices, and takes as given the choices of governments in other countries. Following Lucas and Stokey (1983), the allocation of the 
Ramsey equilibrium maximizes the government's utility function among implementable allocations:

$$
\begin{aligned}
\max _{\left\{c_{i} \geq 0, n_{i} \in[0, \bar{n}], g \geq 0\right\}_{i \in I}} & \sum_{i \in I} \pi_{i} u\left(c_{i}, n_{i}, g\right) \\
\text { subject to: } & u_{c}\left(c_{i}, n_{i}, g\right) c_{i}+u_{n}\left(c_{i}, n_{i}, g\right) n_{i}=0 \text { for } i \in I \\
& \sum_{i \in I} w_{i}\left(u\left(c_{i}, n_{i}, g\right)\right)\left(c_{i}+g\right) \leq \sum_{i \in I} w_{i}\left(u\left(c_{i}, n_{i}, g\right)\right) x_{i} n_{i}
\end{aligned}
$$

Notice that we write the feasibility constraint with inequality instead of equality. This allows to determine the sign of the associated multiplier without affecting the solution, since the feasibility constraint is binding at the optimum.

The Lagrangian is

$$
\mathcal{L}=\sum_{i \in I}\left\{\pi_{i} u\left(c_{i}, n_{i}, g\right)+\lambda_{i}\left[u_{c}\left(c_{i}, n_{i}, g\right) c_{i}+u_{n}\left(c_{i}, n_{i}, g\right) n_{i}\right]+\mu w_{i}\left(u\left(c_{i}, n_{i}, g\right)\right)\left(x_{i} n_{i}-c_{i}-g\right)\right\}
$$

where $\lambda_{i}, i \in I$, are the Lagrange multipliers associated with the implementability constraints, and $\mu \geq 0$ is the Kuhn-Tucker multiplier associated with the feasibility constraint.

Assuming that the solution satisfies $c_{i}>0, n_{i} \in(0, \bar{n})$ and $g>0$, and that it satisfies the feasibility constraint with equality, the necessary conditions are

$$
\begin{aligned}
& \frac{\partial \mathcal{L}}{\partial c_{i}}=\left(\pi_{i}+\lambda_{i}\right) u_{c}+\lambda_{i} u_{c c} c_{i}+\lambda_{i} u_{n c} n_{i}-\mu w_{i}+\mu w_{i}^{\prime} u_{c}\left(x_{i} n_{i}-c_{i}-g\right)=0 \text { for } i \in I \\
& \frac{\partial \mathcal{L}}{\partial n_{i}}=\left(\pi_{i}+\lambda_{i}\right) u_{n}+\lambda_{i} u_{c n} c_{i}+\lambda_{i} u_{n n} n_{i}+\mu w_{i} x_{i}+\mu w_{i}^{\prime} u_{n}\left(x_{i} n_{i}-c_{i}-g\right)=0 \text { for } i \in I \\
& \frac{\partial \mathcal{L}}{\partial g}=\sum_{i \in I}\left[\pi_{i} u_{g}+\lambda_{i}\left(u_{c g} c_{i}+u_{n g} n_{i}\right)-\mu w_{i}+\mu w_{i}^{\prime} u_{g}\left(x_{i} n_{i}-c_{i}-g\right)\right]=0 \\
& \frac{\partial \mathcal{L}}{\partial \lambda_{i}}=u_{c} c_{i}+u_{n} n_{i}=0 \text { for } i \in I \\
& \frac{\partial \mathcal{L}}{\partial \mu}=\sum_{i \in I} w_{i}\left(x_{i} n_{i}-c_{i}-g\right)=0
\end{aligned}
$$

where the arguments of the functions have been suppressed for readability. The previous is a system of $2+3 I$ equations in the $2+3 I$ unknowns $\left\{c_{i}, n_{i}, g, \lambda_{i}, \mu\right\}_{i \in I}$.

So far, we have not made any reference to the other countries. We now recall that all countries are identical, and we focus on a symmetrical equilibrium where all governments choose the same fiscal policy and the same Ramsey equilibrium. Then, each household 
receives the same utility in all countries, no household migrates in equilibrium, and the number of type $i$ households $w_{i}$ in each country is constant and equal to $\bar{w}_{i}>0$. We then substitute $w_{i}=\bar{w}_{i}$ in the previous system.

\section{The effect of migration feasibility on optimal fiscal policy}

We illustrate the key mechanism analytically using the following benchmark economy.

Let the utility function be

$$
u(c, n, g) \equiv A[\alpha \log (c)+(1-\alpha) \log (g)]-\Phi \frac{n^{1+\varphi}}{1+\varphi}
$$

where $A>0, \alpha \in(0,1), \Phi>0$ and $\varphi>0$. The utility function is separable in its three arguments, and the elasticity of substitution between private and public consumption is constant and equal to 1 . Although $\lim _{n \rightarrow \bar{n}} u_{n}(c, n, g)=-\Phi \bar{n}^{\varphi}>-\infty$ we assume that $\bar{n}$ is large enough so that the solution is still described by the previous necessary conditions.

Recall that the population weights $w_{i}$ are constant and equal to $\bar{w}_{i}$ in symmetrical equilibria where all countries implement the same fiscal policy. In addition, assume that the sensitivities $w_{i}^{\prime}$ are constant and equal to $\gamma \bar{w}_{i}, \gamma>0$, so the population weights are locally linear in welfare.

We are interested on the equilibrium effects of changes in the sensitivity $\gamma$ of migration to welfare. We first establish that aggregate variables do not depend on $\gamma$.

Notice that $u_{c c}(c, n, g) c=-u_{c}(c, n, g), u_{n n}(c, n, g)=\varphi u_{n}(c, n, g)$ and all the cross second derivatives are equal to zero. Then, the necessary conditions are

$$
\begin{aligned}
{\left[\pi_{i}+\mu \gamma \bar{w}_{i}\left(x_{i} n_{i}-c_{i}-g\right)\right] u_{c}\left(c_{i}, n_{i}, g\right)-\mu \bar{w}_{i} } & =0 \text { for } i \in I \\
{\left[\pi_{i}+\lambda_{i}(1+\varphi)+\mu \gamma \bar{w}_{i}\left(x_{i} n_{i}-c_{i}-g\right)\right] u_{n}\left(c_{i}, n_{i}, g\right)+\mu \bar{w}_{i} x_{i} } & =0 \text { for } i \in I \\
\sum_{i \in I}\left\{\left[\pi_{i}+\mu \gamma \bar{w}_{i}\left(x_{i} n_{i}-c_{i}-g\right)\right] u_{g}\left(c_{i}, n_{i}, g\right)-\mu \bar{w}_{i}\right\} & =0 \\
u_{c}\left(c_{i}, n_{i}, g\right) c_{i}+u_{n}\left(c_{i}, n_{i}, g\right) n_{i} & =0 \text { for } i \in I \\
\sum_{i \in I} \bar{w}_{i}\left(x_{i} n_{i}-c_{i}-g\right) & =0
\end{aligned}
$$


Notice that both the first and the third equation imply that $\mu \neq 0$, so $\mu>0$.

From the implementability constraint,

$$
\begin{aligned}
u_{c}\left(c_{i}, n_{i}, g\right) c_{i}+u_{n}\left(c_{i}, n_{i}, g\right) n_{i} & =0 \\
A \alpha-\Phi n_{i}^{1+\varphi} & =0
\end{aligned}
$$

so labor only depends on preferences' parameters and does not depend on $\gamma$. Clearly, since labor $n_{i}$ does not depend on $\gamma$, aggregate production $\sum_{i \in I} \bar{w}_{i} x_{i} n_{i}$ does not depend of $\gamma$ either. Also, labor $n_{i}$ is the same for all types of households, and differences in households' welfare are only determined by differences in households' private consumption $c_{i}$.

Multiplying the first-order condition for $c_{i}$ by $c_{i}$, summing across types, and using the goods market equilibrium condition, we obtain

$$
\begin{aligned}
\sum_{i \in I}\left\{\left[\pi_{i}+\mu \gamma \bar{w}_{i}\left(x_{i} n_{i}-c_{i}-g\right)\right] A \alpha-\mu \bar{w}_{i} c_{i}\right\} & =0 \\
A \alpha-\mu \sum_{i \in I} \bar{w}_{i} c_{i} & =0
\end{aligned}
$$

Multiplying the first-order condition for $g$ by $g$, and using the goods market equilibrium condition, we obtain

$$
\begin{array}{r}
\sum_{i \in I}\left\{\left[\pi_{i}+\mu \gamma \bar{w}_{i}\left(x_{i} n_{i}-c_{i}-g\right)\right] A(1-\alpha)-\mu \bar{w}_{i} g\right\}=0 \\
A(1-\alpha)-\mu \sum_{i \in I} \bar{w}_{i} c_{i}=0
\end{array}
$$

Summing up the two previous equations, and using the goods market equilibrium conditions,

$$
\begin{aligned}
A-\mu \sum_{i \in I} \bar{w}_{i}\left(c_{i}+g\right) & =0 \\
A-\mu \sum_{i \in I} \bar{w}_{i} x_{i} n_{i} & =0
\end{aligned}
$$

Recalling that aggregate production does not depend on $\gamma, \mu$ does not depend on $\gamma$ either. Then,

$$
\begin{array}{r}
A \alpha-\mu \sum_{i \in I} \bar{w}_{i} c_{i}=0 \\
\alpha \sum_{i \in I} \bar{w}_{i} x_{i} n_{i}-\sum_{i \in I} \bar{w}_{i} c_{i}=0
\end{array}
$$


and similarly $(1-\alpha) \sum_{i \in I} \bar{w}_{i} x_{i} n_{i}=g$, so aggregate private consumption and public consumption are constant fractions $\alpha$ and $1-\alpha$ of aggregate production, and do not depend on $\gamma$

We are now ready to derive the equilibrium effect of changes in $\gamma$. It is convenient to introduce the concept of net fiscal contribution (or net fiscal burden). Let $\delta_{i} \equiv \tau_{i} x_{i} n_{i}-g$ be the net fiscal contribution of type $i$ households. Let type $i$ households be called net fiscal contributors if $\delta_{i}>0$, and net fiscal beneficiaries if $\delta_{i}<0$. From the government's budget constraint, $\sum_{i \in I} \bar{w}_{i} \delta_{i}=0$, so if some types of households are net fiscal contributors, some other types of households are net fiscal beneficiaries. Also, using the households' budget constraints, $\delta_{i}=x_{i} n_{i}-c_{i}-g$.

From the first-order condition for consumption,

$$
\begin{array}{r}
{\left[\pi_{i}+\mu \gamma \bar{w}_{i}\left(x_{i} n_{i}-c_{i}-g\right)\right] u_{c}\left(c_{i}, n_{i}, g\right) c_{i}-\mu \bar{w}_{i} c_{i}=0} \\
{\left[\pi_{i}+\mu \gamma \bar{w}_{i}\left(x_{i} n_{i}-c_{i}-g\right)\right] A \alpha-\mu \bar{w}_{i} c_{i}=0}
\end{array}
$$

Recalling that $n_{i}, g$ and $\mu$ do not depend on $\gamma$,

$$
\begin{aligned}
\left(x_{i} n_{i}-c_{i}-g\right) A \alpha d \gamma & =(\gamma A \alpha+1) d c_{i} \\
\frac{d c_{i}}{d \gamma} & =\frac{\left(x_{i} n_{i}-c_{i}-g\right) A \alpha}{\gamma A \alpha+1} \\
\frac{d c_{i}}{d \gamma} & =\frac{\delta_{i} A \alpha}{\gamma A \alpha+1}
\end{aligned}
$$

so consumption $c_{i}$ and welfare $u\left(c_{i}, n_{i}, g\right)$ are increasing with $\gamma$ for net fiscal contributors, while they are decreasing with $\gamma$ for net fiscal beneficiaries. Moreover, since $\delta_{i}=x_{i} n_{i}-c_{i}-g$ and $\left(1-\tau_{i}\right) x_{i} n_{i}=c_{i}$, the net fiscal contribution and the tax rate is decreasing with $\gamma$ for net fiscal contributors while they are increasing with $\gamma$ for net fiscal beneficiaries. In the limiting case that $\gamma \rightarrow \infty, \delta_{i}=x_{i} n_{i}-c_{i}-g \rightarrow 0$, so the net fiscal contributions $\tau_{i} x_{i} n_{i}-g$ of all types of households tend to zero. The case $\gamma \rightarrow \infty$ can be interpreted as the case with free mobility and a very small country relative to the rest of the world (or an infinite number of countries).

This is the fundamental insight of the model. Without migration $(\gamma=0)$, the optimal fiscal policy implies that some households are net fiscal contributors while the other are net 
fiscal beneficiaries. Clearly, if the number of net fiscal contributors could increase, taxes could decrease and public consumption could increase, so all households would benefit. Hence, with migration $(\gamma>0)$, the government has an extra-incentive to attract net fiscal contributors, and tilts its fiscal policy in their favor, decreasing their net fiscal contribution and their tax rate, and increasing their welfare. The reverse is true for net fiscal beneficiaries. The larger the sensitivity of migration to welfare $\gamma$, the larger this effect. In the limiting case that $\gamma \rightarrow \infty$, all households are zero net fiscal contributors.

To help intuition, it is useful to consider the benchmark case that $\pi_{i}=\bar{w}_{i}$, for $i \in I$. In this case,

$$
\begin{array}{r}
{\left[\pi_{i}+\mu \gamma \bar{w}_{i}\left(x_{i} n_{i}-c_{i}-g\right)\right] A \alpha-\mu \bar{w}_{i} c_{i}=0} \\
{\left[1+\mu \gamma\left(x_{i} n_{i}-c_{i}-g\right)\right] A \alpha-\mu c_{i}=0}
\end{array}
$$

so consumption $c_{i}$ and welfare $u\left(c_{i}, n_{i}, g\right)$ are increasing in productivity $x_{i}$. Then,

$$
\begin{array}{r}
{\left[1+\mu \gamma\left(x_{i} n_{i}-c_{i}-g\right)\right] A \alpha-\mu c_{i}=0} \\
\left(1+\mu \gamma \delta_{i}\right) A \alpha-\mu c_{i}=0
\end{array}
$$

so the net fiscal contribution $\delta_{i}$ is also increasing in productivity $x_{i}$. Using $\sum_{i \in I} \bar{w}_{i} \delta_{i}=0$ it follows that $\delta_{i}>0$ for households with productivity higher than a threshold, and $\delta_{i}<0$ for households with productivity lower than the threshold. In this case, then, governments compete to attract high productivity households and to discourage low productivity households, and modify their fiscal policy accordingly.

Also, in this case, we can derive how migration feasibility affects social welfare as expressed by the government's utility function. Recalling that $n_{i}, g$ and $\mu$ do not depend on $\gamma$

$$
\frac{d\left(\sum_{i \in I} \pi_{i} u\left(c_{i}, n_{i}, g\right)\right)}{d \gamma}=\sum_{i \in I} \pi_{i} \frac{A \alpha}{c_{i}} \frac{d c_{i}}{d \gamma}=A \alpha \frac{A \alpha}{\gamma A \alpha+1} \sum_{i \in I} \pi_{i} \frac{\delta_{i}}{c_{i}}
$$

Recall that both consumption $c_{i}$ and the net fiscal contribution $\delta_{i}$ are increasing in productivity $x_{i}$, so consumption and the net fiscal contribution are increasing functions of each other. It follows that

$$
\sum_{i \in I} \pi_{i} \frac{\delta_{i}}{c_{i}}<\sum_{i \in I} \pi_{i} \delta_{i} \sum_{i \in I} \pi_{i} \frac{1}{c_{i}}=0
$$


where the last equality follows from $\sum_{i \in I} \pi_{i} \delta_{i}=\sum_{i \in I} \bar{w}_{i} \delta_{i}=0$. Equivalently, with a slight abuse of notation,

$$
\sum_{i \in I} \pi_{i} \frac{\delta_{i}}{c_{i}} \equiv E(\delta / c)=E(\delta) E(1 / c)+\operatorname{Cov}(\delta, 1 / c)<E(\delta) E(1 / c)=0
$$

where the last equality follows from $E(\delta)=\sum_{i \in I} \pi_{i} \delta_{i}=\sum_{i \in I} \bar{w}_{i} \delta_{i}=0$. Hence, as the sensitivity $\gamma$ of migration to welfare increases, the equilibrium social welfare decreases, in line with analogous findings in the fiscal competition literature.

\section{Conclusion}

In this paper, we have emphasized an equilibrium effect of migration on optimal fiscal policy. The more feasible is migration, the larger is the change of fiscal policy in favor of net fiscal contributors and at the expenses of net fiscal beneficiaries. In the limit, with free mobility, all households are zero net fiscal contributors.

We hope this paper will stimulate work along several directions. In the paper, we modelled the migration decision by households with a reduced form function $w_{i}\left(u\left(c_{i}, n_{i}, g\right)\right)$ of their equilibrium utility. It would be interesting to explicitly study a game with several countries and limited mobility, deriving endogenously the determinants of the migration decision. We are confident that the main result will hold in the Nash equilibrium of the game. However, in the infinite repetition of the stage game, we expect subgame perfect equilibria will exist where countries cooperate and obtain better outcomes than that one of the Nash equilibrium of the stage game.

Moreover, the tools and the results developed in the paper should help characterize the optimal fiscal policy with migration in other relevant economies. For instance, it seems reasonable to suppose that, in the case of different valuations of a public good across households, the more feasible is migration, the closer to the net fiscal contributors' preferences should be the provision of the public good. Also, the more feasible migration, the lower the tax rate for factors provided by net fiscal contributors, and the higher the tax rate for factors provided by net fiscal beneficiaries.

Finally, it would be important to evaluate empirically the quite precise, although nor- 
mative, implication of the model. The model predicts that, the more households are able and willing to migrate into and out of an economy, the smaller should be the observed differences across households' net fiscal contributions. A very interesting test for the model would be comparing the differences across households' net fiscal contributions for states and provinces, where households are more able and willing to migrate, and for countries, where the sensitivity of migration to welfare differences is smaller.

\section{References}

Honkapohja, S. and A. Turunen-Red (2004). Gains and losses from tax competition with migration. University of New Orleans, Department of Economics and Finance w.p. 2004-01.

Lucas, R. E. J. and N. L. Stokey (1983). Optimal fiscal and monetary policy in an economy without capital. Journal of Monetary Economics 12 (1), 5593.

Razin, A. and E. Sadka (2001). Labor, Capital and Finance: International Flows. Cambridge University Press.

Razin, A., Sadka, E. and P. Swagel (2002). Tax burden and migration: a political economy theory and evidence. Journal of Public Economics 85, 167-190.

Storesletten, K. (2000). Sustaining fiscal policy through immigration. Journal of Political Economy 108 (2), 300-323.

Wilson, J. D. (1999). Theories of tax competition. National Tax Journal 52(2), 269-304. 